\title{
Flower Bud Differentiation, Mega-micro Spore Production, and Male-female Gametophyte Development in Camellia weiningensis
}

\author{
Hongli Wei, Chao Gao, Jie Qiu, Zhiyan Guo, Biao Wang, and Li Long \\ Institute for Forest Resources and Environment of Guizhou, Key Laboratory of Forest Cultivation \\ in Plateau Mountain of Guizhou Province, College of Forestry, Guizhou University, Guiyang \\ 550025, China
}

\begin{abstract}
AdDitional INDEX wORDs. alpine plant, embryology, observation, paraffin sectioning, reproductive system
Abstract. Camellia weiningensis is a typical woody edible oil tree species in the northwest alpine area of Guizhou Province, China, but its embryological development is not fully elucidated. Here, we assessed flower bud differentiation, microsporogenesis, and male-female gametophyte development in this species. We performed cytological observations of flower bud development in $C$. weiningensis through conventional paraffin sectioning, scanning electron microscopy, and stereomicroscopy to establish the corresponding relationships between the external morphology and internal structure. The flowers were hermaphroditic and exhibited a short flower bud differentiation time. Although pistil development occurred later than stamen development, both organs matured synchronously before flowering. The anther contained four sacs that exhibited a butterfly shape in transverse sections. The anther wall comprised the epidermis, anther chamber inner wall, two middle layers, and a glandular tapetum (from outside to inside). Microspore mother cells formed a tetrahedral tetrad through meiosis, mature pollen was two-celled with three germination pores, and the ovary comprised three to five chambers (three chambers predominated). Multiple ovules were invertedly attached to the axial placentation and exhibited double integuments and a thin nucellus. The embryo sac exhibited Allium-type development, and the mature embryo sac was seven-celled and eight-nucleated. In $C$. weiningensis, embryonic development does not exhibit abnormalities, and stamen development occurs earlier than pistil development. During flower bud development, the inner development process of male and female cells can be judged according to their external morphological characteristics. Our results may provide a theoretical basis for regulating flowering in and the cross-breeding of $C$. weiningensis.
\end{abstract}

Every link of plant reproductive development is affected by multiple factors; during this process, any defect can cause reproductive process failure, which may threaten the survival of the species (Gao, 2002). In seed plants, flower bud differentiation, mega-micro spore production, and male-female gametophyte development constitute the core of plant embryology, and failure in any of these links can cause seed abortion and thereby lead to a low yield (Liang et al., 2005). In Ziziphus jujuba, the presence of abnormal sacs during megasporogenesis and female gametogenesis tends to cause embryo abortion at a late stage and thus result in yield reduction (Shao et al., 2019). In Platycladus orientalis, the lack of a well-developed tapetum to provide nutrition during microsporogenesis causes macrovoid sporangia and thereby leads to sterility (Liao et al., 2021). In Actinidia deliciosa, programmed cell death can cause cytoplasmic agglutination within microspores, which leads to hollow microspores (Coimbra et al., 2004). The formation of an abnormal cytoplasm

Received for publication 20 Sept. 2021. Accepted for publication 17 Dec. 2021.

Published online 8 February 2022

This work was supported by the National Natural Science Foundation of China (32060331, 31800516), Science and Technology Plan Project of Guizhou Province of China (Qian Ke He zhicheng[2019]2310), Science and Technology Project of Guizhou Education Department (Qian Jiao He KY[2018]097), Cultivation Project of Guizhou University ([2019]35), and Research Project of Introducing Talents in Guizhou University ([2017]41). We thank Zhi Jiayin for his help in sampling.

C.G. is the corresponding author. E-mail: gaochao@gzu.edu.cn.

This is an open access article distributed under the CC BY-NC-ND license (https://creativecommons.org/licenses/by-nc-nd/4.0/). or irregular sporangia is associated with the duration of the development of tapetal and middle layer cells (Zini et al., 2012). In Koelreuteria elegans, the occurrence of programmed deaths of tapetal, septal, and intermediate cells during the initiation of microsporogenesis can cause failure in anther dehiscence (Avalosa et al., 2019). In the Magnoliaceae species Manglietia aromata (Pan et al., 2003) and Manglietia decidua (Xiao and Xu, 2006), the loss of most synergids during sac development can lead to a high oocyte abortion rate. Pollen abnormalities during any process from microspore mother cell meiosis to pollen maturation and dehiscence will cause pollen sterility (GonzalezMelendi et al., 2008). Embryological characteristics serve as an important basis for judging compatibility between plant species and for determining the process of plant evolution (Johri et al., 1992). Among the 11 species of Scilla, the development of the embryo sac in most species is of the Allium type, and that in one of the species is of the Drusa type (Svoma and Greilhuber, 1989). The degeneration modes of the nucelli and integuments of Koelreuteria and Dodonaeaeae (both Sapindaceae) after megasporogenesis are the same (Gonzalez et al., 2017). Therefore, male-female gametophyte development plays a crucial role in the continuation of species populations (Chen, 2010).

Alpine mountain areas are special habitats for plant growth and are normally characterized by harsh and changeable environments. In these areas, environmental factors, such as temperature, air pressure, and air density, decrease as the altitude increases. Moreover, these areas are characterized by strong radiation, large temperature differences, and large daily variations. The special environmental conditions in alpine areas not 
only reduce the activity of plant pollinators but also exert an influence on plant embryonic development (Kudo and Suzuki, 2002; Scheffknecht et al., 2007); however, the studies on the embryology of alpine plants remain far from systemic and complete (Körner, 1999). A small number of studies have reported that swollen and persistent antipodal cells can accelerate the growth of embryos of alpine biennial ephemeral plants and promote the process of seed maturation (Akhakatsi and Wagner, 1996; Wagner and Mittehofer, 1998). In recent years, the embryonic development of Camellia has been investigated by several research groups (Ariyarathna et al., 2011; Yuan et al., 2011; Zou et al., 2013).

Camellia weiningensis is an important woody oil tree species grown in high-altitude mountainous areas in northwestern Guizhou Province, China. The distribution of this species is narrow and is concentrated in alpine areas with an elevation of $\approx 1600$ to $3000 \mathrm{~m}$ in Guizhou Province. The fruit setting rate of $C$. weiningensis is very low, which has substantially restricted its economic output. Although Camellia has been shown to exhibit high self-incompatibility (Chang et al., 2016), the research on the internal reasons for this low fruit setting rate of $C$. weiningensis remains far from systemic and complete. Based on the aforementioned information, this study investigated flower bud differentiation, mega-micro spore production, and male-female gametophyte development in this species. The results of this study might provide practical guidance and a theoretical basis for the high-yield cultivation and genetic improvement of $C$. weiningensis and provide basic data for further research on the reproductive biology and developmental biology of Camellia. Furthermore, the results of this study may provide a theoretical basis for regulating flowering in $C$. weiningensis and for the cross-breeding of this species.

\section{Materials and Methods}

\section{Experimental site}

All flower buds were collected from 30-year-old small trees that were grown from wild seedlings and bore the same genotype. All experimental materials used in this study were obtained from the Camellia Research Station of Guizhou University, which is located in Weining County, Bijie, China (lat. $104^{\circ} 7^{\prime} 53^{\prime \prime}$ E, long. $27^{\circ} 11^{\prime} 53^{\prime \prime} \mathrm{N}$ ). The station lies at an elevation of $2200 \mathrm{~m}$ and experiences an annual average precipitation of $909 \mathrm{~mm}$, an annual average temperature of $11.5^{\circ} \mathrm{C}$, an annual average maximum temperature of $16^{\circ} \mathrm{C}$, and an annual average frost-free period of $206 \mathrm{~d}$.

At this station, the number of annual average sunshine hours is $1812 \mathrm{~h}$. The annual temperature difference is small, whereas the daily temperature difference is large. The soil is yellowbrown, and routine water (once per month) and fertilization were provided twice each year (March and September, respectively).

\section{Methods}

Fifteen trees with consistent growth, a strong tree body, and normal flowering and fruiting were randomly selected as the experimental subjects. Sampling was performed from May 2019 (beginning of flower bud differentiation) to Feb. 2020 (initiation of the flowering period), and 30 flower buds of uniform size around the crown were collected from each tree once per week. The phenological time of flower bud differentiation and development was investigated and recorded. During flower bud differentiation, the collected flower buds were observed by paraffin sectioning and scanning electron microscopy (SEM). After differentiation, the stamens and pistils of the buds were subjected to paraffin sectioning and stereomicroscopy, and photographs were taken.

In addition, photographs of the external morphology of the buds were taken. The collected buds were placed in Carnoy's stationary liquid [ethanol:chloroform:acetic acid $(6: 3: 1 \mathrm{v} / \mathrm{v} / \mathrm{v})$ ] for $12 \mathrm{~h}$ and then transferred into $70 \%$ alcohol solution for preservation at $4{ }^{\circ} \mathrm{C}$.

Routine PARAFFIN SECTION PREPARATION AND OBSERVATION. Specimens were prepared using a routine paraffin sectioning method (Wang et al., 2011). The fixed anthers and ovules were removed from the alcohol solution, immediately placed in hematoxylin dye, and maintained in the dark at room temperature for $7 \mathrm{~d}$ of staining. The specimens were then subjected to gradient dehydration with different concentrations of alcohol $(30 \%, 50 \%$, $70 \%, 85 \%, 90 \%$, and $100 \%$, sequentially), xylene transparency treatment, and paraffin embedding. Sections with a thickness of 6 to $8 \mu \mathrm{m}$ were prepared using an ultrathin semiautomatic microtome (RM2235; Leica, Wetzlar, Germany). Xylene dewaxing and permanent sealing with Canadian balsam were then performed. Photographs were taken under an optical microscope (DM2500, Leica).

SEM. Fresh flower buds at each period were collected. Half of the flower bud was carefully cut off with tweezers and a scalpel (transversely for some buds and longitudinally for the rest). The prepared bud was then fixed with $2.5 \%$ glutaraldehyde fixative solution (prepared with $0.1 \mathrm{~mol} \cdot \mathrm{L}^{-1}$ phosphate buffer) at $4{ }^{\circ} \mathrm{C}$ for $2 \mathrm{~h}$, subjected to three or four 10 -min washes with phosphate buffer, fixed with $1 \%$ osmium tetroxide (prepared with 0.1 $\mathrm{mol} \cdot \mathrm{L}^{-1}$ phosphate buffer) at $4{ }^{\circ} \mathrm{C}$ for $2 \mathrm{~h}$, and washed three or four times with phosphate buffer. The specimen then underwent gradient dehydration with ethanol at concentrations of $30 \%$, $50 \%, 70 \%, 80 \%, 90 \%$, and $95 \%$ and a final set of three treatments at $100 \%$. Afterward, the specimen was successively treated with ethanol-tert-butanol $(3: 1,2: 2$, and 1:3) for $10 \mathrm{~min}$ and then subjected to a final treatment with $100 \%$ tert-butanol, freezing, and drying. The treated specimen was attached to the sample platform with conductive tape and coated with an ionsputtering instrument (MSP-mini; IXRF, Austin, TX) for $30 \mathrm{~s}$. Images were obtained under an SEM (TM4000Plus; Hitachi, Ibaraki, Japan) (conditions: voltage of $10 \mathrm{kV}$, high vacuum, and BSE electronic mode).

Stereomicroscopy. During flower bud differentiation (from May to Oct. 2019), flower buds at different periods were selected. Single buds were collected from the branches, and the scales were removed. The whole process during which the flower bud gradually opens was sequentially photographed and observed under a stereomicroscope (KL300 LED; Leica).

\section{Results}

\section{Flower bud differentiation}

Spring shoots (vegetative shoots germinated from the flower buds in the preceding year) started to emerge in mid and late February, and small, sharp, and tender buds (flower buds germinated from the vegetative shoots emerging in February) gradually emerged in late May. In early June, most of the flower buds elongated and entered the differentiation stage. However, the differentiation of trees with a low stand density and sufficient light conditions occurred earlier than that of trees with a high stand 
density and poor light conditions, but the difference was not substantial. Differences could also be observed among trees and among buds at different positions in the same tree (Table 1).

The flowers of $C$. weiningensis are hermaphroditic flowers, and the buds started to germinate after the growth of spring shoots ended. Based on the bud sections and the morphological differentiation characteristics of the bud growth cone determined by SEM observations, we divided the differentiation process of C. weiningensis flower buds into seven stages: nondifferentiated stage, predifferentiation stage, sepal formation stage, petal formation stage, stamen formation stage, pistil formation stage, and ovary-anther formation stage. The anatomic morphological characteristics of the different stages are as follows:

1) Nondifferentiated stage (Fig. 1A1-C1). In mid-May, the growing bud presented a small volume. Because flower buds and leaf buds are homogeneous organs, these organs were difficult to differentiate in terms of morphology at an early stage. Based on the longitudinal sections, the flower buds of $C$. weiningensis at this time point remained at the vegetative growth stage. During this stage, the flower bud did not start to differentiate. The terminal bud cells presented a similar shape, and cell activity began to increase. The growth cone exhibited a protrusion, which was not obvious.

2) Predifferentiation stage (Fig. 1A2-C2). Flower buds entered the predifferentiation stage in early June. The flower bud appeared oval, with a blunt and sharp front end, and the flower bud was small. At this stage, the morphology of the growth point tissue began to gradually change: The apical meristem transitioned to reproductive growth, the longitudinal division of the cells in the growth point accelerated, and the growth point appeared semiconical and slightly raised. During the late period, the base gradually widened, the flower bud gradually expanded, and the flower bud could be distinguished from the leaf bud. SEM observations were consistent with those based on paraffin sections (Fig. 2A).

3) Sepal formation stage (Figs. 1A3-C3 and 2B). In the middle of June, the growth cone at the top end of the growth point turned from a semiconical shape to an oblate shape, and the top continued to widen and sagged downward. The differentiation of the surrounding cells accelerated. With the continuous differentiation and extension of the cells, protrusion from the calyx primordium appeared near the growth cone. Septa covered the growth point. At the early period, the septum exhibited a flat rectangular shape, and at the late period, it became larger and ultimately developed into an expanded septum. In terms of appearance, the septa grew horizontally and transversely, and the base of the flower bud expanded.
4) Petal formation stage (Figs. $1 \mathrm{~A} 4-\mathrm{C} 4$ and $2 \mathrm{C}$ ). On $\approx 20$ June, petals formed inside the flower bud. The top of the growth point became smooth from a sharp circle, and the growth point widened. With the differentiation and elongation of the sepals, a ring of small protrusions formed on both sides during the late period of sepal formation, which corresponded to the early manifestation of petal differentiation. As the petal primordium continued to grow upward, the top appeared sharp and round with a wide middle section, and the bottom was slightly narrower than the middle section. The longitudinal growth of the petal primordium was faster than the transverse growth, and the length of the petal primordium was larger than its width. The petal primordium ultimately developed into petals. At this time point, the flower buds appeared round and wide and elongated. As a result, the flower bud exhibits a clearly different appearance from that of the leaf bud.

5) Stamen formation stage (Fig. 1A5-C5). With the differentiation and elongation of the calyx and petal primordia, the growth point continued to extend around and to sag downward. A number of small protrusions arose from the middle, which corresponds to preliminary formation of the stamen primordium. Subsequently, the stamen primordium continued to grow, its top turned round and thick, and the base gradually widened to show a clavate shape. Anthers formed at the top of the stamens, and filaments formed at the base. The stamen primordia grew concentrically from inside to outside and were arranged in two to three rounds, and the flower bud continued to become round, long, and wide.

6) Pistil formation stage (Fig. 1A6-C6). In early July, the growth cone at the center and base of the stamen primordium gradually began to form a wide, small protrusion, which is considered the pistil primordium, and at this stage, the pistil primordium was slightly narrow at the top and wide at the base. A top view showed three holes at the top of the pistil primordium, which constituted the basis of style development (Fig. 2D-F). The growth of the flower bud accelerated.

7) Ovary-anther formation stage (Figs. 1A7-A9, B7-B9, C7-C9, and $2 \mathrm{G}-\mathrm{I}$ ). On $\approx 15$ July, after formation of the stamens and pistils, the base of the pistil primordium expanded to form an ovary, and the longitudinal growth at the top of the primordium accelerated. The primordium gradually closed to the middle from an opening state and aggregated to form the stigma and ovary chambers (three to five chambers). Within the chamber, multiple ovules were attached to the axial placentation. The growth of the stamen primordium accelerated along the horizontal and transverse directions with the style as the center. At this moment, all the anthers and four pollen sacs had formed, and the

Table 1. Relationship between the bud differentiation time of Camellia weiningensis and the stand density.

\begin{tabular}{|c|c|c|c|c|c|}
\hline \multirow[b]{2}{*}{ Date } & \multicolumn{5}{|c|}{ Stand density $(\%)$} \\
\hline & 0 & 10 & 30 & 50 & 70 \\
\hline 25 May & Predifferentiation & Predifferentiation & Nondifferentiation & Nondifferentiation & Nondifferentiation \\
\hline 8 June & Sepal formation & Sepal formation & Predifferentiation & Predifferentiation & Predifferentiation \\
\hline 15 June & Petal formation & Petal formation & Sepal formation & Sepal formation & Sepal formation \\
\hline 23 June & Stamen formation & Stamen formation & Petal formation & Petal formation & Petal formation \\
\hline 28 June & Pistil formation & Pistil formation & Stamen formation & Stamen formation & Stamen formation \\
\hline 8 July & Ovary and anther formation & $\begin{array}{l}\text { Ovary and anther } \\
\text { formation }\end{array}$ & Pistil formation & Pistil formation & Pistil formation \\
\hline 19 July & Tender anther formation & $\begin{array}{l}\text { Tender anther } \\
\text { formation }\end{array}$ & $\begin{array}{l}\text { Ovary and anther } \\
\text { formation }\end{array}$ & $\begin{array}{l}\text { Ovary and anther } \\
\text { formation }\end{array}$ & $\begin{array}{l}\text { Ovary and anther } \\
\text { formation }\end{array}$ \\
\hline
\end{tabular}




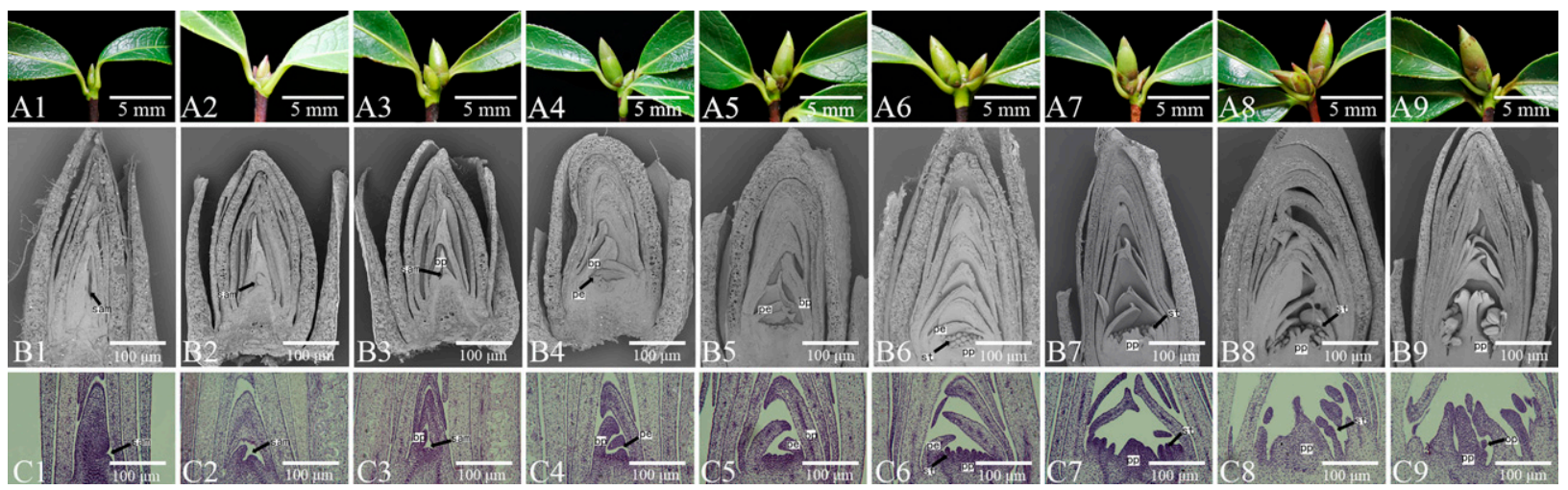

Fig. 1. Observations of flower bud differentiation in Camellia weiningensis through stereomicroscopy (A), scanning microscopy (B), and optical microscopy (C): (A1, B1, C1) Flower buds are nondifferentiated; (A2, B2, C2) growth point changes from pointed to round; (A3, B3, C3) top of the growth point becomes flat, and the calyx primordium appears; $(\mathbf{A 4}, \mathbf{B 4}, \mathbf{C 4})$ growth point continues to flatten, and the petal primordium appears; (A5, B5, C5) growth point extends in all directions, and the stamen primordium begins to form; (A6, B6, C6) stamen primordium continuously differentiates and extends; (A7, B7, C7) stamen primordium protrudes; (A8, B8, C8) pistil and stamen primordia continuously extend; (A9, B9, C9) differentiation process of the flower bud is completed. $\mathrm{sam}=$ shoot apical meristem; $\mathrm{bp}=$ bract primordium; $\mathrm{pe}=$ petal primordium; $\mathrm{st}=$ stamen primordium; $\mathrm{pp}=$ pistil primordium; ov $=\mathrm{ovary}$; op $=$ ovule primordium.

anthers developed from three rounds to four rounds. The flower bud continued to elongate, became wider, and was wrapped by five to six sepals, which were hairless, and the bottom of the flower bud gradually began to exhibit a light purple color.

\section{Microsporogenesis and male gametophyte development}

ANTHER Wall DEVelopment. The initial structure of the anther of $C$. weiningensis was simple. It was composed of four chambers, and two of these chambers were symmetrically
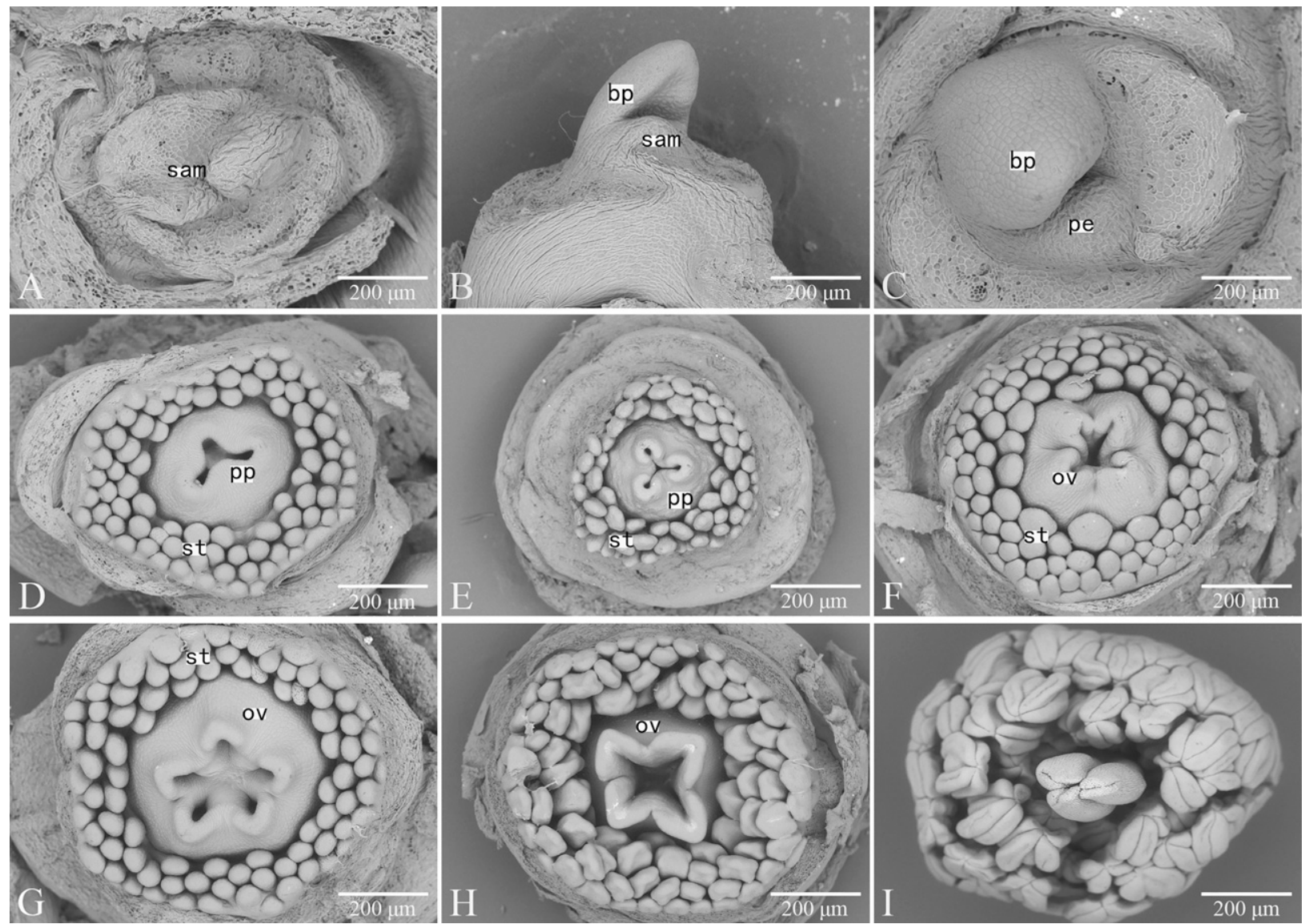

Fig. 2. Top view of the differentiation of flower buds in Camellia weiningensis through scanning electronic microscopy: (A-C) Appearance of the calyx and petal primordia, $(\mathbf{D}-\mathbf{H})$ differentiation and growth processes of the pistil and stamen primordia, $(\mathbf{I})$ completion of flower bud differentiation. sam $=$ shoot apical meristem; $\mathrm{bp}=$ bract primordium; $\mathrm{pe}=$ petal primordium; $\mathrm{st}=$ stamen primordium; $\mathrm{pp}=$ pistil primordium; ov $=\mathrm{ovary}$. 
distributed on each side and separated by a septum composed of parenchyma cells and vascular bundles. The anther exhibited an overall butterfly shape. The outside of the anther comprised a layer of protoepidermis, and the inside contained a group of meristems with active proliferation that exhibited a similar morphology. During the anther growth process, its four corner cells formed four cracked valves. Under the epidermis of the valve, archesporial cells differentiated. All archesporial cells underwent one periclinal division to form a layer of primary parietal cells (inside) and a layer of primary sporogenous cells (outside) (Fig. 3A). After multiple periclinal and anticlinal divisions, primary parietal cells formed the inside and outside layers of secondary parietal cells, and each layer was composed of multiple, concentrically arranged secondary parietal cells. Before the division of microspore mother cells, the outside layer of secondary parietal cells developed to form the inner and middle layers of the anther chamber, whereas the secondary parietal cells in the insider layer formed the middle layer and tapetum (Fig. 3B). Epidermal cells and primary parietal cells were completely differentiated after multiple divisions. The completely differentiated anther wall was composed of five layers of cells: epidermis, inner wall of the anther chamber, middle layers (two layers), and tapetum, from the outside to inside. The development type of the anther wall of $C$. weiningensis was the basic type, and the cells of all layers of the anther wall matured during the development of microspores and male gametophytes.

The epidermis was the outermost cell of the anther wall and only underwent vertical division, which aimed to cater to the rapid expansion of the inner tissues. At the early stage of anther development, the epidermal cells comprised a layer of large and closely arranged rectangular cells with detectable nuclei (Fig. $3 \mathrm{~B})$. With the growth and expansion of the anther, the epidermal cells extended and became flat to maintain consistency with the growth of the inner tissues. At the initial stage of the microspore mother cells, vacuolization began to appear in the epidermal cells (Fig. 3C). When the anther matured, the epidermal cells displayed a noticeable cuticle structure, and irregular-shaped protrusions formed (Fig. 3I).

The inner wall of the anther chamber was composed of a layer of small rectangular cells that were neatly arranged. These cells were located on the inner side of the epidermis (Fig. 3B). At the mononuclear microspore mother cell stage, the inner wall contained starch granules (Fig. 3C) and grew in the back-end radial direction. During the tetrad period, the inclusions were reduced, and the inner wall was noticeably thickened (Fig. 3D). When the anther matured and pollen was about to disperse, the cells in the inner wall of the anther exhibited maximal development, as demonstrated by a noticeable cuticle and thickened

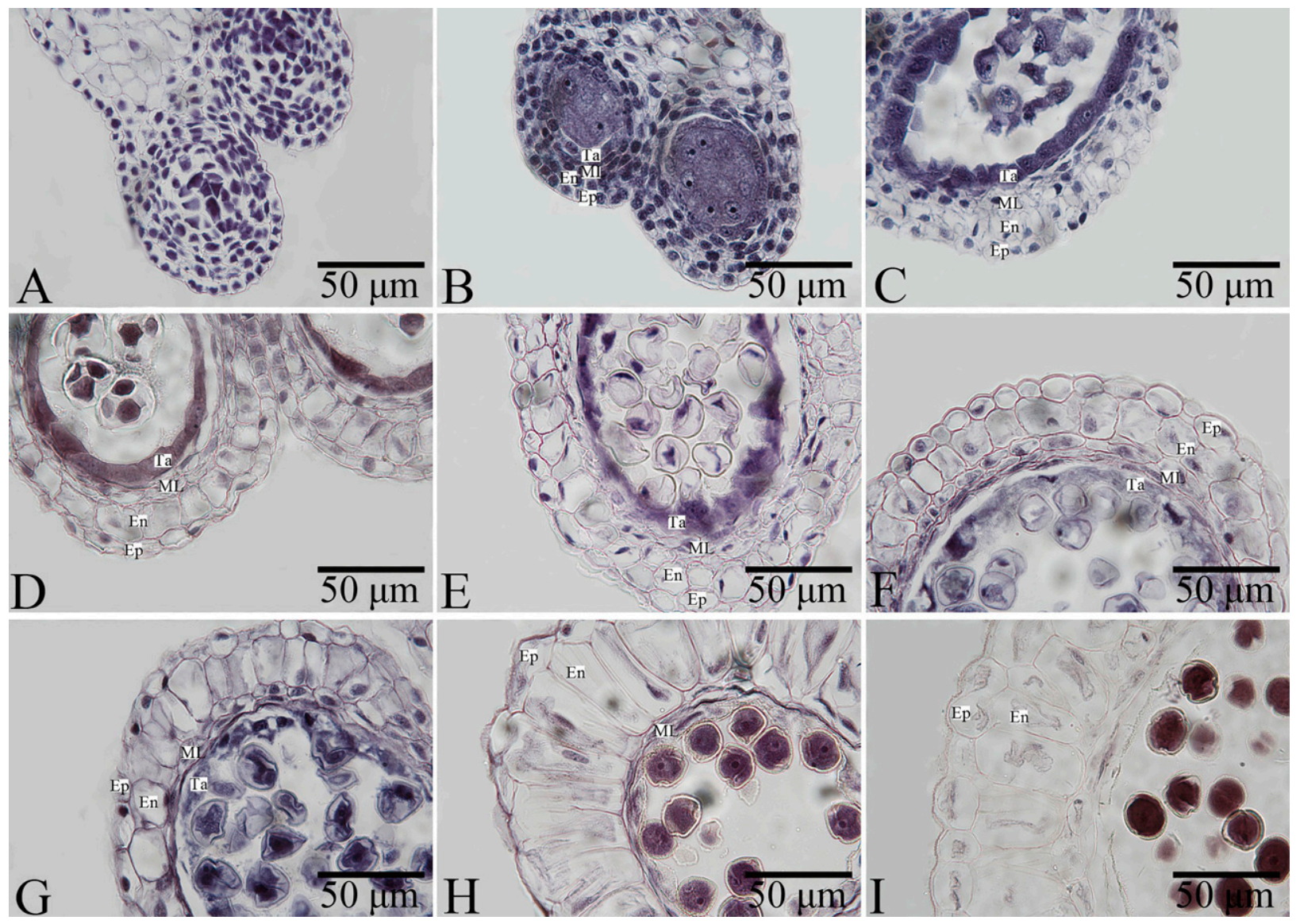

Fig. 3. Observations of the development of the anther wall in Camellia weiningensis under an optical microscope: (A) primary sporogenous cells, (B) formation of the anther wall, $(\mathbf{C})$ thickened tapetum, (D) gradual vacuolization of the tapetum, (E) continued vacuolization of the tapetum, (F) continued disintegration of the tapetum, $(\mathbf{G})$ thickened inner wall of the anther chamber and gradually absorbed middle-layer cells, $(\mathbf{H})$ continued thickening of the inner wall of the anther chamber, (I) only a folded epidermis and a thickened fibrous layer remain in the inner wall of the anther chamber. $\mathrm{EP}=\mathrm{epidermis;} \mathrm{EN}=\mathrm{endothecium}$; $\mathrm{ML}=$ middle layer; $\mathrm{Ta}=$ tapetum. 
fibers (Fig. 3G-I). No fibrous thickening occurred between two anther sacs on the same side. The cell arrangement gap was large, which was conducive to anther sac cracking and pollen release.

The middle-layer cells were composed of two layers of flat parenchyma cells. Their morphology did not markedly change during development of the anther. During the tetrad stage of microspore mother cells, the middle-layer cells began to degenerate with the progression of meiosis (Fig. 3D), and at the end of pollen maturation, these cells were fully absorbed and disintegrated, with only residues remaining (Fig. 3I).

The tapetum is the innermost layer of cells adjacent to sporogenous cells, which begin to develop at the stage of secondary sporogenesis. At this time point, the tapetum was characterized by a dense cytoplasm and few vacuoles (Fig. 3B). At the early stage of meiosis, tapetal cells exhibited maximal development, with abundant cytoplasm, and the nucleus and nucleolus could be clearly observed (Fig. 3C). During the microspore tetrad stage, the tapetum cells disintegrated in situ and then gradually vacuolated (Fig. 3D). Pollen grains gradually expanded, and the tapetum was further disintegrated but remained connected to the middle layer (without complete disintegration) (Fig. 3E and F). During development of the anther to the stage of pollen maturation, the tapetal cells were completely absorbed by pollen grains. Throughout the development process, the tapetum remained in situ and belonged to the secretory type (Fig. 3G and H). Finally, only folded epidermis and a thickened fibrous layer remained in the anther wall (Fig. 3I).

Microsporogenesis. From late July to early August, the stamen primordium grew upward, and young anthers formed at the top (Fig. 4A). On both the left and right sides of the young anther, two pollen sacs developed, and in these sacs, several cells constituted sporogonia (Fig. 4B). After periclinal division, sporogonia developed into primary sporogenous cells (Fig. 4C). After several rounds of mitosis, primary sporogenous cells developed into secondary sporogenous cells. After one more division, the secondary sporogenous cells developed into microspore mother cells. Microspore mother cells presented a clearly observed nucleus with a dense cytoplasm around the nucleus, and their morphology substantially differed from that of the wrapped anther wall (Fig. 4D). The area surrounding the microspore mother cells exhibited increased accumulation of callose, which was the source of nutrition for the pollen mother cells, and single microspore mother cells formed (Fig. 4E and F). The duration of meiosis in $C$. weiningensis was short. In the middle of August, at the prophase stage of meiosis of the microspore mother cells, the chromosomes gradually condensed, and the nucleus became larger (Fig. 4G). In metaphase, the chromosomes were arranged in two pairs along the equatorial plate at the center of the cell to form spindles (Fig. 4H). At the later stage, homologous chromosomes separated from each other and then migrated to the poles (Fig. 4I). Subsequently, the second round of meiosis started: the cell divided into four nuclei, and after cytoplasmic division, the nuclei formed tetrads, which exhibited a tetrahedral appearance and were surrounded by a wall of callose (Fig. 4J and K). However, despite a large number of observational experiments conducted before and after meiosis, we only observed a few stages of meiosis due to the short time span of meiosis. The processes of meiosis between different anthers and between different anther chambers were basically consistent. The cytoplasmic division of microspore mother cells of $C$. weiningensis belonged to the simultaneous type.

Male Gametophyte development. Male gametophyte development originated from microspores. The early tetrad microspores that had formed after meiosis at the end of August were not immediately separated, and due to their tetrahedral morphology, they were wrapped by translucent callose (Fig. 4K). From early September to mid-September, callose was ablated, and the tetrahedral microspores were released into the anther chamber. At this time point, the microspores had a small size and dense cytoplasm without obvious bubbles. Afterward, the cell wall gradually thickened, and the cells became gradually vacuolated to form mononuclear pollen grains with the nucleus located at the center (Fig. 4L-N). At the end of September, as the mononuclear pollen grains rapidly expanded, a large central vacuole appeared; the nucleus was squeezed to one side of the cell, and the pollen gradually entered the uninucleate stage (Fig. 4O). In early and middle October, the microspore nucleus close to the pollen wall underwent mitosis and developed into a small lenticular germ cell close to the pollen wall and a large round vegetative cell in the middle of the cell. The volume of the pollen grain markedly increased, and nutrients gradually accumulated within it (Fig. 4P and Q). The grains were oval or elliptical in shape and exhibited a dense cytoplasm. The tapetum was completely dissolved, and the outer wall of the anther became noticeably thickened (Fig. 4R). Throughout our observation of the pollen grain development process, the pollen grains were round and full, and no abnormal phenomena, such as empty and shriveled grains, deformation, or a small size, were observed.

\section{Megasporogenesis and female gametophyte development}

Megasporogenesis. Camellia weiningensis had a superior ovary, which was composed of three to five carpels and contained multiple chambers. Ovaries with three carpels and three chambers were the dominant type (Fig. 5A and B). Each chamber contains multiple axial-placentation ovules with a thin nucellus. According to the cross-section of the ovary, ovules developed from the ovule primordium on the placenta. In the central part of the cells under the epidermis of the inner chamber, a mass of slightly bulged cells appeared after periclinal division, and this mass constituted the ovule primordium. The cells of the ovule primordium underwent periclinal and anticlinal divisions. The nucellus developed from the front of the ovule primordium, and the funicle developed from the base (Fig. 5C). The epidermal cells close to the base of the nucellus continued to grow and divide, and a circular uplift was produced, became gradually extended, and developed into integuments. The process included the development of the inner integument followed by that of the outer integument. The nucellus was wrapped by the integuments, which were classified as a double-integument type. A gap was observed between the outer integument and the inner integument (Fig. 5D and E). The inner tissue under the nucellus epidermis differentiated into sporogonia, which formed megaspore mother cells after one mitosis (Fig. 5F). During the development process, the micropyle end bended toward the petiole end to form inverted ovules (Fig. 5D). The megaspore mother cells underwent meiosis to form megaspore dyads and tetrads (Fig. 5G-I).

Female Gametogenesis. Functional megaspores continued to undergo the meiosis process to develop into mononuclear embryo sacs, and their volume increased. The formation of 

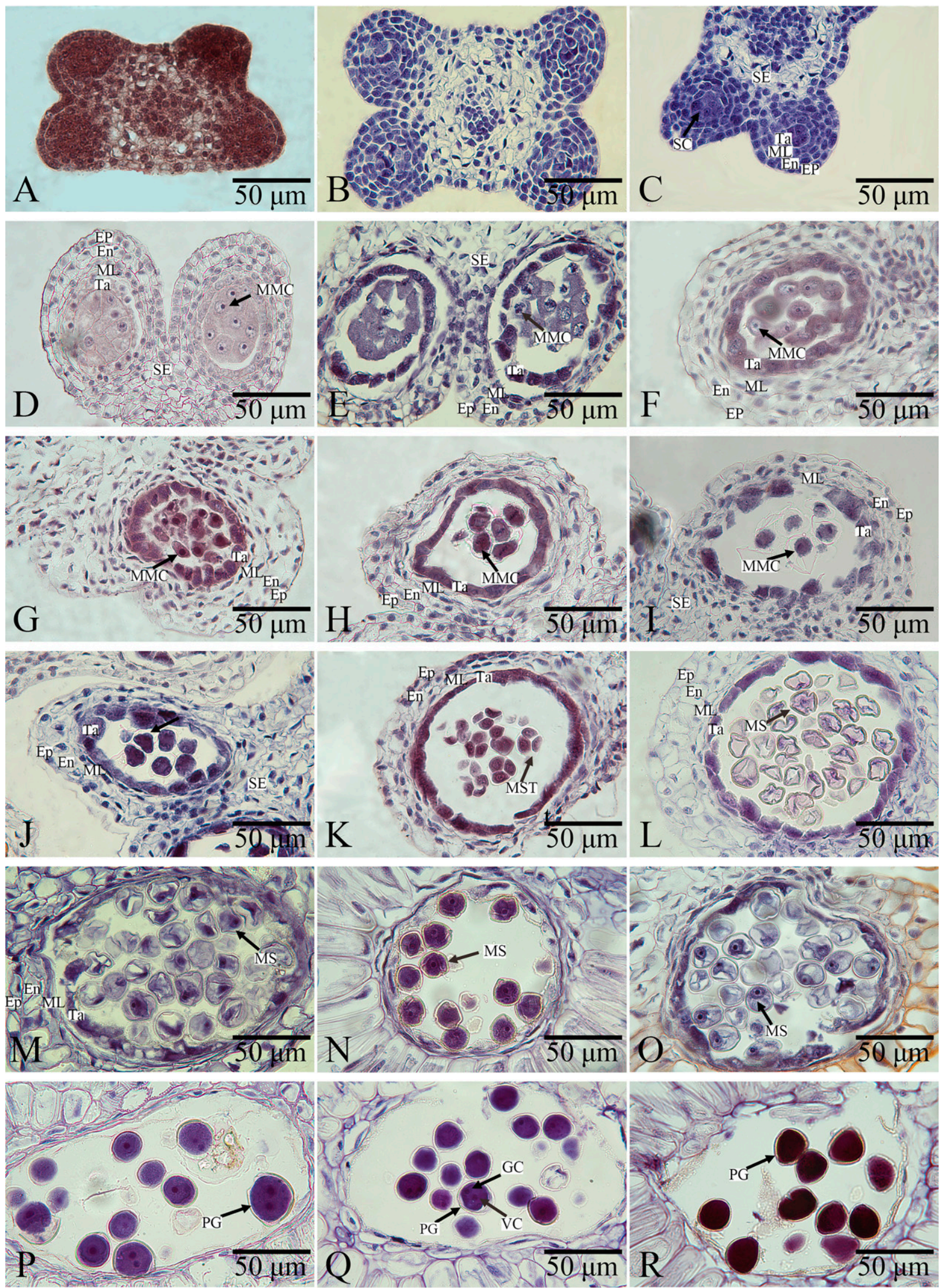

Fig. 4. Observations of male gametophyte development in Camellia weiningensis under an optical microscope: (A) transverse section of the young anther, (B) four pollen sacs begin to form, $(\mathbf{C})$ primary sporogenous cell, $(\mathbf{D})$ microspore mother cell, $(\mathbf{E})$ gradual decomposition of callose, $(\mathbf{F})$ single microspore mother cells, $(\mathbf{G}-\mathbf{J})$ meiotic period, $(\mathbf{K})$ tetrad period, $(\mathbf{L})$ gradual expansion of pollen grains, $(\mathbf{M})$ stage of the microspore central nucleus, $(\mathbf{O})$ microspore mononuclear-side state, $(\mathbf{P})$ binuclear pollen stage, $(\mathbf{Q})$ vegetative nucleus and reproductive nucleus, $(\mathbf{R})$ mature pollen grains. $\mathrm{EP}=$ epidermis; $\mathrm{EN}=$ endothecium; $\mathrm{ML}=$ middle layer; $\mathrm{Ta}=$ tapetum; $\mathrm{SE}=$ septum; $\mathrm{SC}=$ sporogenesis cell; $\mathrm{MMC}=$ microspore mother cell; $\mathrm{MST}=$ microspore tetrad; $\mathrm{MS}=$ microspore; $\mathrm{PG}=$ pollen grain; $\mathrm{GC}=$ generative cell; $\mathrm{VC}=$ vegetative cell . 

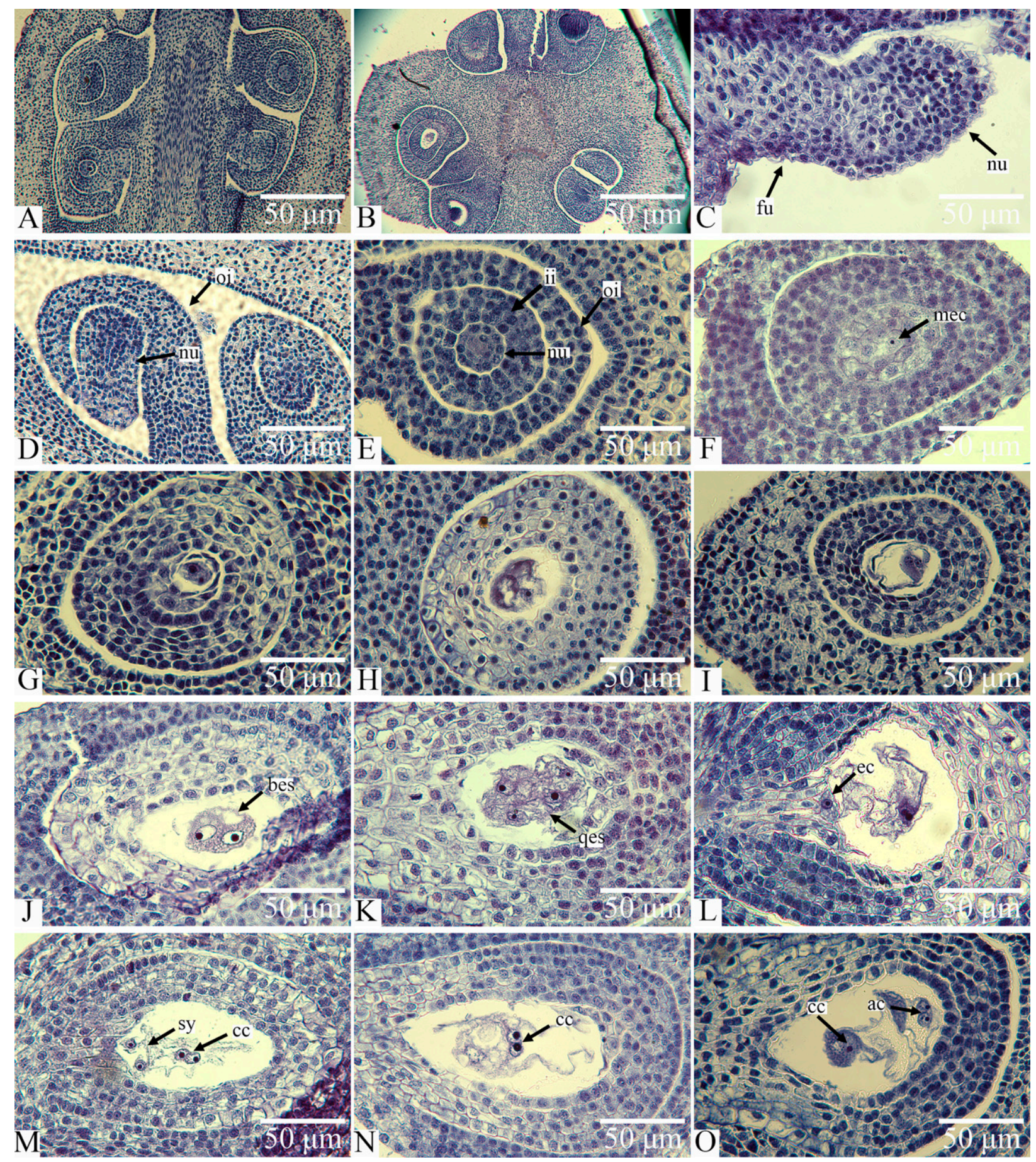

Fig. 5. Observations of female gametophyte development in Camellia weiningensis under an optical microscope: (A, B) Longitudinal and transverse sections; (C) front end of the ovule develops into the nucellus, and the base develops into the funicle; (D) nucellus is gradually surrounded by the integument; (E) nucellus has been surrounded by the integument; (F) megaspore mother cell; (G) dyad; (H, I) dyad meiosis; (J) binuclear embryo sac; (L-O) seven-celled eight-nucleated embryo sac; mec $=$ megaspore mother cell; bes $=$ binucleate embryo sac; qes $=$ qi-nucleated embryo sac; ec $=$ egg cell; sy = synergid; $c c=$ central cell; ac = antipodal cell; $\mathrm{nu}=$ nucellus; $\mathrm{ii}=$ inner integument; oi = outer integument.

mononuclear embryo sacs served as the sign of female gametophyte development. Mononuclear embryo sacs needed three rounds of mitosis. After the first mitosis, they developed into binuclear embryo sacs (Fig. 5J). The two nuclei underwent another mitosis at the micropyle and chalazal ends and developed into a four-nuclear embryo sac. The volume of the embryo sac continued to increase, and large vacuolization occurred (Fig.
$5 \mathrm{~K})$. The four nuclei then developed into eight nuclei after the third mitosis. The embryo sac further expanded. A nucleus from the micropyle end and one from the chalazal end moved toward the center and were ultimately fused into a two-polar nucleus cell at the center of the embryo sac (Fig. $5 \mathrm{~N}$ ). The micropyle end with the developed filamentous apparatus had one egg cell and two synergids, which were collectively referred to as the 
egg apparatus (Fig. 5L and M). The two synergids were closely arranged with a dense cytoplasm. The three nuclei at the chalazal end were antipodal nuclei (Fig. 5O). According to the observations based on consecutive sections of the embryo sac, the development of the embryo sac of $C$. weiningensis belonged to the Allium type.

\section{External morphological characteristics of pistil and stamen development}

Based on observations, the development processes of pistils and stamens were closely related to their own morphological changes, and the different morphologies of pistils and stamens could basically indicate a certain development period (Table 2), although the representativeness was not completely absolute. This finding indicated the accuracy and feasibility of our sampling and the asynchronous development of megaspore and microspore mother cells. Approximately 1 week after the stamens appeared, they became flat and transparent; the pistils were shorter than the stamens, the color of the style was light cyan, and the ovary was hairless. At this time point, the stamens formed four pollen sacs (Fig. 6A1-C1). The pistils and stamens continued to elongate and develop. The stamens remained transparent, the color of the style turned cyan, and the ovary was hairless. This period was considered the primary sporogenesis period (Fig. 6A2-C2). The stamens grew transversely and longitudinally, the anther was transparent, the ovary was expanded with small transparent villi on the surface, and the color of the style changed from cyan to green. This period constituted the microspore mother cell stage (Fig. 6A3-C3). The anther gradually became full and exhibited a light yellow color. The ovary continued to expand, and the style extended. This period was the male gametophyte formation stage (Fig. 6A4-C4). The color of the anther deepened, and the villi on the surface of the ovary extended and exhibited a white color. This period corresponded to the binuclear pollen stage (Fig. 6A5-C5). The color of the stamens changed from light yellow to bright yellow. The plumpness of the anther reached the maximum. The pistils were further prolonged, and the stigma appeared trifid with openings along three directions. The stamens surrounded the pistils. This period was known as the pollen grain maturation stage (Fig. 6A6-C6).

Based on observations of the morphology of the stamens and pistils, $C$. weiningensis is monoecious and hermaphroditic. The flower was fully grown. Within one flower, the development of pistils occurred slightly later than that of stamens; however, their late development accelerated, and stamens and pistils matured simultaneously once the flower entered the blossoming stage.

\section{Discussion}

The differentiation of flower buds constitutes the premise of flower formation, and the transformation process from leaf buds to flower buds is an indispensable link in the formation of flower organs (Bernier and Perilleux, 2005). Therefore, investigating the characteristics and periods of flower bud differentiation and ensuring the quality and quantity of plant flower buds are of great significance to production (Yamasaki et al., 2003). The morphological differentiation of the flower buds of $C$. weiningensis started at the end of May and was completed by the end of June and early July of the same year, which indicated that it lasted $\approx 30 \mathrm{~d}$. In the alpine plant system, most plants bloom in spring and summer. The short time and fast speed of flower bud differentiation in $C$. weiningensis might be adaptations to the extreme environment of alpine mountainous areas.

Based on observations performed in the current study, the differentiation process of the flower bud of $C$. weiningensis can be divided into seven stages: nondifferentiated stage, predifferentiation stage, sepal formation stage, petal formation stage, stamen formation stage, pistil formation stage, and ovary and anther formation stage. Our finding was consistent with that reported by He (2009) for $C$. oleifera. Furthermore, we found that the stamen primordium of $C$. weiningensis appeared earlier than the pistil primordium. In contrast, in Camellia nitidissima and Camellia flavida, the differentiation of the pistil primordium occurs after the formation of multiple rows of stamen primordia (La et al., 2021). The differentiation time of the flower buds of different

Table 2. Correspondence between the development of megaspores, microspores, and male and female gametophytes and the external morphology of the flower bud, stamens, and pistils in Camellia weiningensis.

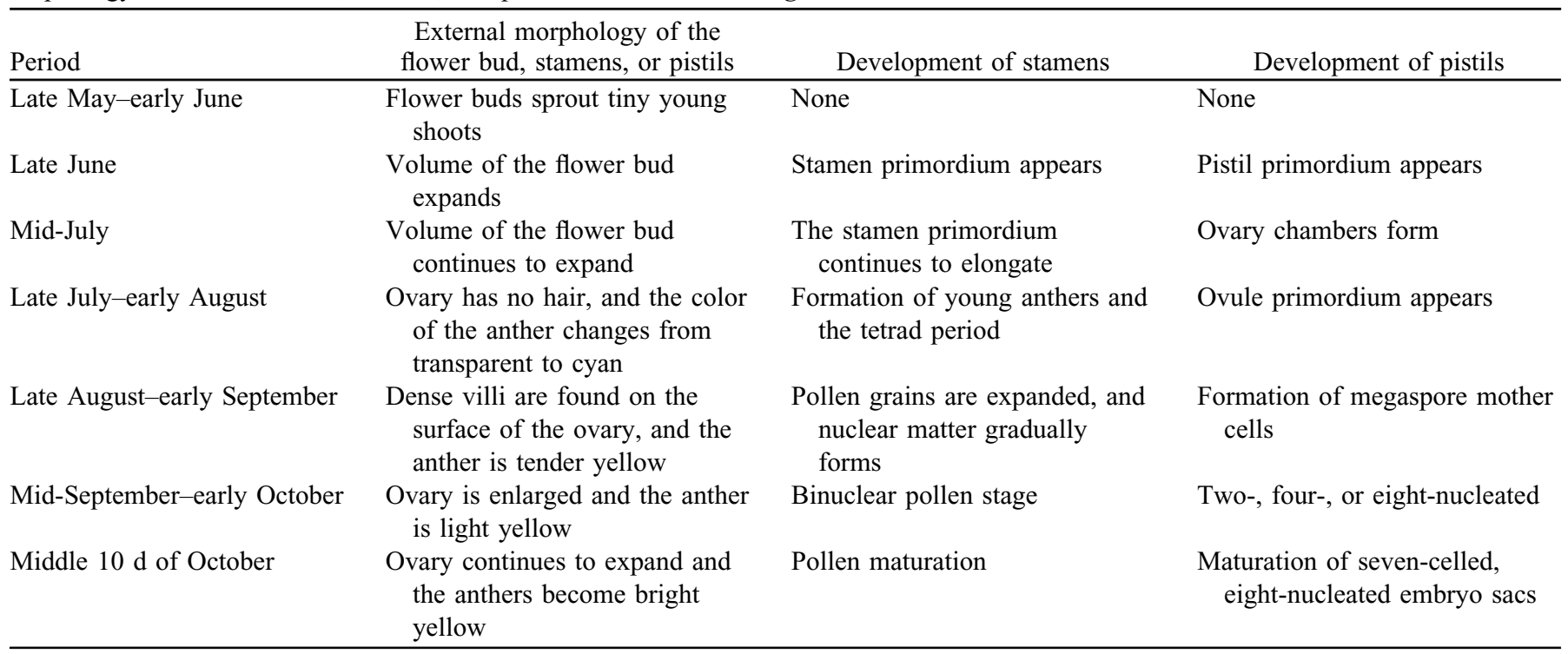




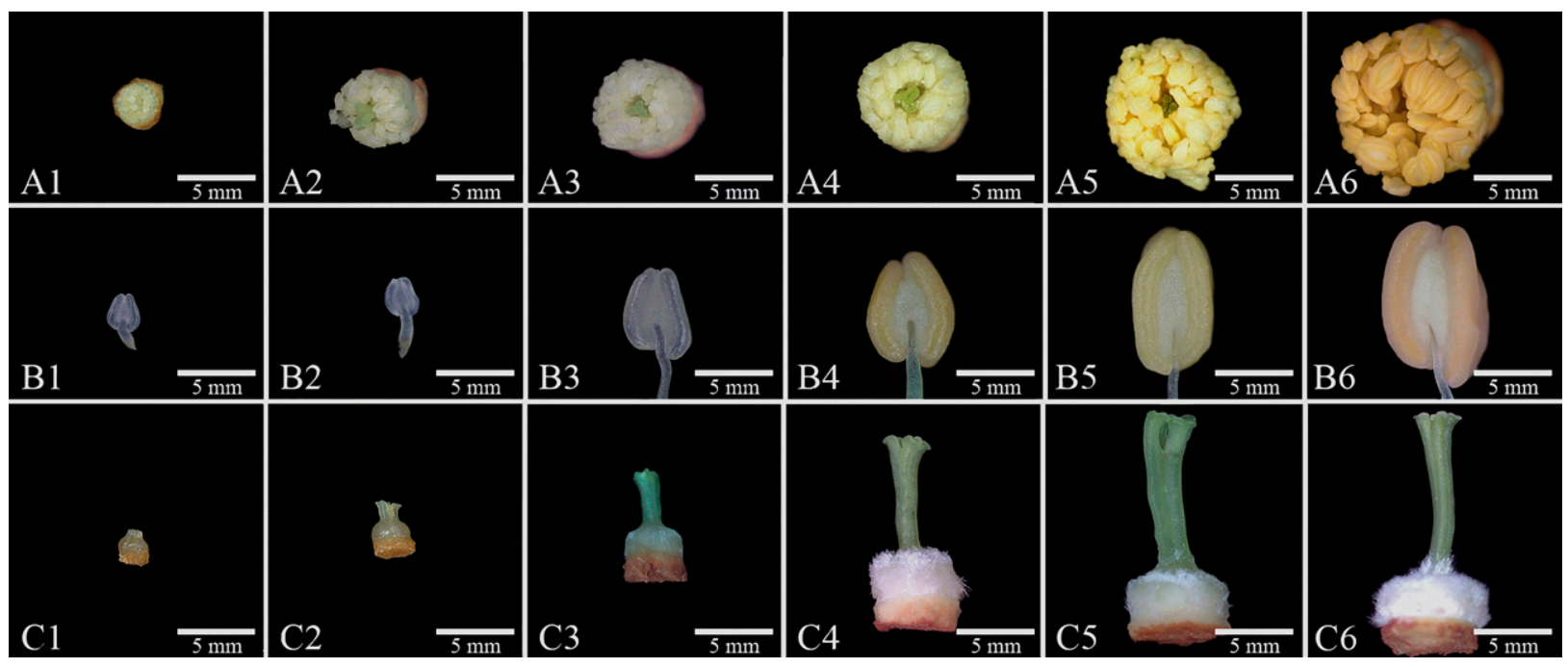

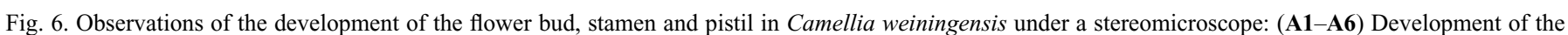
flower bud, (B1-B6) development of the stamen, (C1-C6) development of the pistil.

single trees varied slightly, and overlaps between different differentiation stages were sometimes observed.

Detailed studies of the anther wall cells of different species of angiosperms (Huang et al., 2013; Wang et al., 2021) have divided the development mode of the anther wall into four types: basic type, dicotyledonous type, monocotyledonous type, and simplified type. In $C$. weiningensis, the anther wall was composed of the epidermis, inner wall of the anther chamber, two middle layers, and tapetum. The inner wall of the chamber could become thickened to form a fibrous layer. According to the classification of the anther wall formation types reported by Dias and Correia (2002), the flower bud differentiation of $C$. weiningensis belongs to the basic type. The tapetum of $C$. weiningensis is subject to glandular-type development, and the tapeta of the observed samples developed normally. Spore development is closely related to the tapetum structure; an abnormal tapetum structure is harmful to anther maturation and eventually leads to pollen abortion (Ravi et al., 2008; Shao et al., 2011). In this study, we found that mother cell division was of the secretory type: mature pollen contained two-cell grains, and grains contained three germination pores. Normally, the meiotic processes of microspore mother cells should be highly synchronous (Yuan et al., 2011); however, in C. weiningensis, the development processes of the microspore mother cells exhibited an asynchronous characteristic according to different anthers within the same flower and even different chambers within the same anther. This asynchronous phenomenon has been observed in previous studies of microspore meiosis in Lagerstroemia speciosa (Zhu et al., 2018) and Tilia miqueliana (Gao and Shen, 2010). It has been assumed that this effect is the result of the prolonged pollination time of the plant as well as its adaptation to the local environment, which provides a guarantee for the successful reproduction of this species and is therefore of certain positive significance for its evolution (Zhu et al., 2018). In C. weiningensis, even though we performed a large number of observation experiments, only a few phases of meiosis (rather than the complete series of phases) were observed due to the short meiosis duration. The processes of meiosis in $C$. weiningensis were basically consistent between different anthers; the cytoplasmic division of the microspore mother cells of $C$. weiningensis belonged to the simultaneous type. Embryology involves research on the development of anthers, ovules, and seeds, which provides more than 50 traits for analyses of family, genus, and intraspecific and interspecific phylogeny (Tobe, 1989). The embryological characteristics of $C$. weiningensis were similar to those of other reported Camellia species (Tsou, 1997). Throughout our observation process, the flower buds developed normally, and no abnormal phenomena, such as abortion of ovules and egg organs, empty and shriveled pollen grains, pollen deformation, or a small pollen volume, were observed. Although the development of pistils and stamens existed in succession, they reached synchronization before the opening of the flower bud. This asynchronous phenomenon can effectively prolong the pollination period (Gabriela et al., 2008). Therefore, the development of megaspores, microspores, and male and female gametophytes has little effect on the fruiting rate of $C$. weiningensis. By observing the growth of self-pollinated and outcrossed pollen tubes in the stigma via fluorescence microscopy, as well as the anatomic characteristics of self-pollinated pistils, scholars have found that Camellia oleifera exhibits prezygotic self-incompatibility (Gao et al., 2015; Liao et al., 2014); in C. yuhsienensis, C. polyodonta, C. chekiangoleosa, and $C$. semiserrata, the compatibility indices are all lower than 1, and Camellia may exhibit high self-incompatibility (Chang et al., 2016). High self-incompatibility may also constitute one reason for the low fruit setting rate of $C$. weiningensis; however, further studies are needed in the future.

Due to the influence of low temperature or other harsh environments in alpine areas, the numbers of flower-visiting insects are limited, and their frequency of visits at the plant flowers is generally low (Bynum and Smith, 2001; Norgate et al., 2010). During the development processes of $C$. weiningensis, the development of pistils was shorter than that of stamens, which can increase the probability of self-pollination in the presence of few pollinators in alpine areas. Our observations of flower bud differentiation and male and female gametophyte development in $C$. weiningensis may enrich the understanding of flower bud differentiation, flower organ morphogenesis and reproductive biology in Camellia species, provide data for the systematic development and genetic evolutionary relationships of Camellia, and offer meaningful embryological evidence for future systematic classification. These results may also 
provide a scientific basis for the management of the flowering period during $C$. weiningensis cultivation. Our study of the regularity of the external morphology and internal structure differentiation of flower buds may further provide a reliable morphological basis for the expression of developmental functional genes in C. weiningensis and establish an important theoretical basis for revealing the reproductive mechanism of alpine plants.

\section{Literature Cited}

Akhakatsi, M. and J. Wagner. 1996. Reproductive phenology and seed development of Gentianella caucasea in different habitats in the central Caucasus. Flora 191(2):161-168, https://doi.org/10.1016/ S0367-2530(17)30708-9.

Ariyarathna, H.A.C.K., M.T.K. Gunasekare, J.D. Kottawa-Arachchige, R. Paskarathevan, K.K. Ranaweera, and M. Ratnayake. 2011. Morpho-physiological and phenological attributes of reproductive biology of tea (Camellia sinensis (L.) O. Kuntze) in Sri Lanka. Euphytica 181(2):203-215, https://doi.org/10.1007/s10681-011-0399-9.

Avalosa, A.A., L.M. Zinia, M.S. Ferruccia, and E.C. Lattar. 2019. Anther and gynoecium structure and development of male and female gametophytes of Koelreuteria elegans subsp. formosana (Sapindaceae): Phylogenetic implications. Flora 255:98-109, https://doi.org/ 10.1016/j.flora.2019.04.003.

Bernier, G. and C. Perilleux. 2005. A physiological overview of the genetics of flowering time control. Plant Biotechnol. J. 3(1):3-16, https://doi.org/10.1111/j.1467-7652.2004.00114.x.

Bynum, M.R. and W.K. Smith. 2001. Floral movements in response to thunderstorms improve reproductive effort in the alpine species Gentiana algida (Gentianaceae). Amer. J. Bot. 88(6):1088-1095, https:// doi.org/10.2307/2657092.

Chang, W.X., X.H. Yao, and W. Long. 2016. Cross-compatibility of four kinds of Camellia species. Bull. Bot. Res. 36(4):527-534.

Chen, X.Q. 2010. A study of microsporogensis and male gametogenesis in Psammosilene tunicoides (Caryophyllaceae). Ann. Bot. Fenn. 47(3):175-189, https://doi.org/10.5735/085.047.0302.

Coimbra, S., L. Torrão, and I. Abreu. 2004. Programmed cell death induces male sterility in Actinidia deliciosa female flowers. Plant Physiol. Biochem. 42(6):537-541, https://doi.org/10.1016/j.plaphy.2004.05.004.

Dias, U.S. and M.C. Correia. 2002. Effect of medium renovation and incubation temperature regimes on trenched cabbage microsporeculture embryogenesis. Scientia Hort. 93(3-4):205-214, https://doi.org/ 10.1016/S0304-4238(01)00334-X.

Gabriela, G., M. Verdú, J.G. Segarra-Moragues, S.C. GonzálezMartínez, and J.R. Pannell. 2008. Disassortative mating, sexual specialization, and the evolution of gender dimorphism in heterodichogamous Acer opalus. Evolution 62(7):1676-1688, https:// doi.org/10.1111/j.1558-5646.2008.00394.x.

Gao, C., D.Y. Yuan, and Y. Yang. 2015. Anatomical characteristics of self-incompatibility in Camellia oleifera. Scientia Silvae Sinicae 51(2):60-68.

Gao, F. and Y.B. Shen. 2010. Observation on megasporogensis, microsporogensis and development of female and male gametophytes of Tilia miqueliana. J. Forestr. Eng. 24(5):22-25.

Gao, R.M. 2002. Study and improvement on embrygology of rare and endangered plants (in Chinese with English abstract). J. Shanxi Agr. Univ. 22(3):239-245.

Gonzalez, V.V., S.M. Solis, and M.S. Ferrucci. 2017. Embryological studies of Magonia pubescens (Dodonaeaeae, Sapindaceae): Development of male and female gametophytes in both floral morphs and its phylogenetic implications. Aust. Syst. Bot. 30(3):279-289, https:// doi.org/10.1071/SB17021.

Gonzalez-Melendi, P., M. Uyttewaal, C.N. Morcillo, J.R.H. Mora, and S. Fajardo. 2008. A light and electron microscopy analysis of the events leading to male sterility in Ogu-INRA CMS of rapeseed (Brassica napus). J. Expt. Bot. 59(4):827-838, https://doi.org/10.1093/jxb/erm365.
He, C.Y. 2009. The anatomical studies on the process of sexual reproduction of Camellia oleifera (in Chinese with English abstract). Changsha, China, Central South Univ. For. Technol., PhD Diss.

Huang, L.C., L. Jin, and S.Z. Zhang. 2013. Pollen release mechanisms of papilionaceous plants (Faboideae) (in Chinese with an English abstract). Acta Prataculturae Sinica 22(6):305-314.

Johri, B.M., K.B. Ambegaokar, and P.S. Srivastava. 1992. Comparative embryology of angiosperms. Springer-Verlag, Berlin, Germany, http://dx.doi.org/10.1007/978-3-642-76395-3.

Körner, C. 1999. Alpine plant life - Functional plant ecology of high mountain ecosystems. Springer, Berlin, Germany, http://dx.doi.org/ 10.1659/0276-4741(2001)021[0202:APLFPE]2.0.CO;2.

Kudo, G. and S. Suzuki. 2002. Relationships between flowering phenology and fruit-set of dwarf shrubs in alpine fellfields in northern Japan: A comparison with a subarctic heathland in northern Sweden. Arct. Antarct. Alp. Res. 34:185-190, https://doi.org/10.1080/15230430.2002.12003483.

La, Y.F., L.M. Xiao, and H. Huang. 2021. Process of flowering bud differentiation and comparison of morphological characteristics of three species in yellow Camellia (in Chinese with an English abstract). Southwest China J. Agr. Sci. 34(5):977-983, http://dx.doi.org/10.16213/j.cnki. scjas.2021.5.011.

Liang, C.L., M.J. Liu, and J. Zhao. 2005. Research progress on plant abortion (in Chinese with an English abstract). Mol. Plant Breed. 3(1):117-122.

Liao, T., D.Y. Yuan, and F. Zou. 2014. Self-sterility in Camellia oleifera may be due to the prezygotic late-acting self-incompatibility. PLoS One 9(6):e99639, https://doi.org/10.1371/journal.pone.0099639.

Liao, T., G.B. Liu, and L.Q. Guo. 2021. Bud initiation, microsporogenesis, megasporogenesis, and cone development in Platycladus orientalis. HortScience 56(1):85-93, https://doi.org/10.21273/HORTSCI15479-20.

Norgate, M., S. Boyd-Gerny, V. Simonov, M. Rosa, T. Heard, and A.G. Dyer. 2010. Ambient temperature influences Australian native stingless bee (Trigona carbonaria) preference for warm nectar. Plos One 5(8):e12000, https://doi.org/10.1371/journal.pone.0012000.

Pan, Y.Z., H.X. Liang, and X. Gong. 2003. Studies on the reproductive biology and endangerment mechanism of the endangered plant Manglietia arormatic (in Chinese with an English abstract). Acta Bot. Sin. 45(3):31131.

Ravi, M., M.P.A. Marimuthu, and I. Siddiqi. 2008. Gamete formation without meiosis in Ara bidopsis. Nature 451(4182):1121-1124, https:// doi.org/10.1038/nature06557.

Scheffknecht, S., S. Dulinger, G. Grabherr, and K. Hulber. 2007. Mating systems of snowbed plant species of the north-eastern calcareous Alps of Austria. Acta Oecol. 31:203-209, https://doi.org/10.1016/j. actao.2006.09.001.

Shao, F.X., S. Wang, J. Chen, and R.Y. Hong. 2019. Megasporogenesis, microsporogenesis, and development of female and male gametophytes of Ziziphus jujuba Mill. 'Zhongqiusucui'. HortScience 54(10):1686-1693, https://doi.org/10.21273/HORTSCI14237-19.

Shao, T., D. Tang, K.J. Wang, M. Wang, and L.X. Che. 2011. OsREC8 is essential for chromatid cohesion and meta phase I monopolar orientation in rice meiosis. Plant Physiol. 156(3):1386-1396, https://doi.org/ 10.1104/pp.111.177428.

Svoma, E. and J. Greilhuber. 1989. Systematic embryology of the Scilla siberica alliance (Hyacinthaceae). Nord. J. Bot. 8(6):585-600, https://doi.org/10.1111/j.1756-1051.1989.tb01733.x.

Tobe, H. 1989. The embryology of angiosperms: Its broad application to the systematic and evolutionary study. Bot. Mag. 102(2):351-367.

Tsou, C.H. 1997. Embryology of Theaceae - Anther and ovule development of Camellia, Franklinia and Schima. Amer. J. Bot. 84(3):369-381. https://bsapubs.onlinelibrary.wiley.com/doi/10.2307/2446010.

Wagner, J. and E. Mittehofer. 1998. Phenology, seed development, and reproductive success of an alpine population of Gentianella germinica in climatically varying years. Bot. Acta 111:159-166, https:// doi.org/10.1111/j.1438-8677.1998.tb00691.x.

Wang, X., M.Y. Jiang, and S.Y. Lin. 2021. Inflorescence architecture of male and female gametophytes of Sasaella kogasensis 'Aureostriatus' 
(in Chinese with English abstract). J. Anhui Agr. Univ. 48(1):9-14, http://dx.doi.org/10.13610/j.cnki.1672-352x.20210319.017.

Wang, X.N., L.J. Jiang, and Y.Z. Chen. 2011. Observation on morphological and anatomical characteristics of the flower bud differentiation on Camellia oleifera (in Chinese with English abstract). J. Central South Univ. Forest. Technol. 31(8):22-27, 10.14067/j.cnki.1673-923x.2011.08.030.

Xiao, D.X. and F.X. Xu. 2006. Megasporogenesis and development of female gametophyte in Manglietia decidua (Magnoliaceae). Ann. Bot. Fenn. 43(6):437-444.

Yamasaki, S., N. Fujii, and H. Takahashi. 2003. Characterization of ethylene effects on sex determination in cucumber plants. Sex. Plant Reprod. 16(3):103-111, https://doi.org/10.1007/s00497-003-0183-7.

Yuan, D.Y., F. Zou, X.F. Tan, H. Chun-yan, and Y. Jun. 2011. Flower bud differentiation and development of male and female gametophytes in Camellia oleifera (in Chinese with English abstract). J. Central South Univ. Forest. Technol. 31(3): 65-70.

Zhu, L.Q., J. Yuan, and L.D. Wei. 2018. Sporogenesis and gametogenesis of Lagerstroemia speciosa (in Chinese with English abstract). Bull. Bot. Res. 38(2):182-188.

Zini, L.M., B.G. Galati, S.M. Solis, and M.S. Ferrucci. 2012. Anther structure and pollen development in Melicoccus lepidopetalus (Sapindaceae): An evolutionary approach todioecy in the family. Flora 207(10):712-720, https://doi.org/10.1016/j.flora.2012.07.003.

Zou, F., D.Y. Yuan, J.H. Duan, X.F. Tan, and L. Zhang. 2013. A study of microsporgenesis and male gametogenesis in Camellia grijsii Hamce. Adv. J. Food Sci. Technol. 5(12):1590-1595, https://doi.org/10.19026/ ajfst.5.3393. 